\title{
Efeito da Combinação de Óleo de Soja e Monensina na Dieta sobre o Consumo de Matéria Seca e a Digestão em Vacas Lactantes ${ }^{1}$
}

\author{
Eduardo da Costa Eifert ${ }^{2}$, Rogério de Paula Lana ${ }^{3}$, Maria Ignez Leão ${ }^{3}$, Pedro Braga Arcuri ${ }^{4}$, \\ Sebastião de Campos Valadares Filho $^{3}$, Webel Machado Leopoldino ${ }^{2}$, Juliana da Silva Oliveira ${ }^{5}$, \\ Cláudia Batista Sampaio6
}

RESUMO - Quatro vacas lactantes, fistuladas no rúmen, foram distribuídas em um quadrado latino $(4 \times 4)$, com 21 dias de período experimental, sendo os três últimos de avaliação, com a finalidade de avaliar os efeitos da combinação de óleo de soja e monensina sobre o consumo, a digestibilidade total e parcial dos nutrientes, os parâmetros ruminais e a síntese microbiana. Os animais foram dispostos em um arranjo fatorial (2x2) - presença ou ausência de óleo de soja (4\% na MS) e presença ou ausência de monensina na dieta (33 ppm) - e receberam dietas com 55\% de silagem de milho e $45 \%$ de concentrado. Para avaliação da digestibilidade total e parcial, foram coletadas amostras de fezes e de digesta omasal, utilizando FDAi e $\mathrm{Cr}_{2} \mathrm{O}_{3}$ como indicadores. A presença de óleo reduziu o consumo alimentar, mas permitiu similar consumo de NDT. A digestibilidade total de nutrientes não foi afetada pelos tratamentos. A digestibilidade ruminal da FDN foi similar na presença de óleo e na presença de monensina, mas foi reduzida na combinação de ambos. $\mathrm{O}$ pH, a eficiência de síntese microbiana e o total de AGV do líquido ruminal foram similares entre os tratamentos. Observou-se interação entre óleo e monensina para a concentração de $\mathrm{N}_{-} \mathrm{NH}_{3}$, verificando-se menor valor para as dietas com óleo somente. A proporção de acetato foi reduzida tanto pelo óleo como pela monensina, mas em diferentes magnitudes, assim como na combinação. O propionato aumentou com monensina e com óleo, ao passo que o butirato diminuiu com óleo. A relação acetato:propionato foi reduzida na presença de óleo e de monensina. A síntese de proteína microbiana foi reduzida na presença de óleo e ainda mais quando o oléo foi associado à monensina. A combinação de óleo e monensina atua sobre a mesma população microbiana e a sensibilidade à ação da monensina é aumentada na presença de óleo. A limitação no consumo pelo enchimento ruminal, pela redução da digestibilidade da FDN ou pelo incremento energético, não justifica a redução no consumo de matéria seca nas dietas com óleo, indicando que fatores metabólicos podem estar envolvidos.

Palavras-chave: ionóforos, lipídios, parâmetros ruminais, síntese microbiana

\section{Effect of Monensin and Soybean Oil Combination on Dry Matter Intake and Digestibility in Diets Fed to Lactating Cows}

\begin{abstract}
Four rumen fistulated lactating dairy cows were assigned to a Latin Square $(4 \times 4)$, with 21 days of experimental period, being the last three days for evaluation, to evaluate the effects of the combination of soybean oil and monensin in lactating dairy cow diets on dry matter intake, total and partial digestibility of the nutrients and ruminal fermentation and microbial synthesis. The animals were assigned to a factorial arrangement (2x2): presence (4\% in total DM) or absence of soybean oil and presence (33 ppm) or monensin absence and were fed diets with $55 \%$ corn silage and $45 \%$ concentrate. For evaluation of the total and partial digestibility, feces samples and omasal digesta were collected, using ADFi and $\mathrm{Cr}_{2} \mathrm{O}_{3}$ as markers. The oil presence reduced dry matter intake, but allowed similar TND intake. The total digestibility of nutrients was not affected by treatments. The NDF ruminal digestibility was similar in the oil presence and in the monensin presence, but it was reduced in the combination of the two. The $\mathrm{pH}$, the efficiency of microbial synthesis and the total of VFA of the rumen liquor were similar among the treatments. Interaction was observed between oil and monensin for $\mathrm{N}-\mathrm{NH}_{3}$ concentration, being verified smaller value for the diets with oil only. The proportion of acetate was reduced either in the oil presence or in the monensin presence, but in different magnitudes, as well as in the combination of the two. The propionic acid concentration increased with monensin and with oil, and butyric acid decreased with oil. Acetate:propionate ratio was reduced either in the oil presence or in the monensin presence. The synthesis of microbial protein was reduced in the oil presence and still more when oil was associated to monensin. The soybean oil and monensin combination act about the same microbial population and the sensibility to the action of the monensin it is increased in the oil presence. The limitation intake by fill rumen effect, by reduction of NDF digestibility, or by higher energy content, does not justify alone the reduction in dry matter intake in diets with soybean oil, indicating that metabolic factor can be involved.
\end{abstract}

Key Words: ionophores, lipids, microbial synthesis, ruminal fermentation

\footnotetext{
1 Parte da tese de Doutorado do primeiro autor financiada pelo CNPq (processo 477530-01/0 NV).

2 D.S. em Nutrição de Ruminantes pela UFV (eifert@esalq.usp.br).

3 Professor do DZO-UFV, CEP 36571.000 Viçosa - MG.

${ }^{4}$ Pesquisador EMBRAPA Gado de Leite, Juiz de Fora - MG.

${ }^{5}$ Mestranda em Nutrição de Ruminantes, DZO-UFV.

${ }^{6}$ Aluna do curso de Graduação em Zootecnia, DZO-UFV.
} 


\section{Introdução}

O consumo de energia é a principal limitação na produção de leite, que é determinado pela concentração energética da dieta e pela taxa de consumo. As características físico-químicas dos ingredientes da dieta e suas interações podem ter grande efeito sobre o consumo de alimentos por vacas lactantes, influenciando a quantidade de nutrientes disponíveis para a absorção e produção (Allen, 2000).

Com o objetivo de atender aos requerimentos energéticos de vacas em lactação, o uso de lipídios tem sido recomendado para aumentar a densidade energética da dieta, evitando os efeitos nocivos de altas quantidades de concentrados, ricos em amido, sobre o ambiente ruminal (Doreau \& Chilliard, 1997). No entanto, gorduras insaturadas, como o óleo de soja, apresentam efeitos sobre a permeabilidade da membrana microbiana, inibindo principalmente a atividade de bactérias gram-positivas, modificando a fermentação ruminal. Isto resulta em alterações das proporções dos ácidos graxos voláteis (AGV) produzidos, com aumento de propionato e redução nas concentrações de acetato, metano e de amônia ruminal (Nagaraja et al., 1997).

A redução na digestibilidade da fração fibrosa dos alimentos tem sido observada em algumas situações quando há maior teor de gordura na dieta (Jenkins, 1993), o que pode comprometer seu valor energético, em razão de decréscimo na digestibilidade total, e limitar o consumo de matéria seca, em função da maior retenção da fração fibrosa no rúmen (Allen, 2000), reduzindo o consumo total de energia (Palmquist, 1994).

Ionóforos, como a monensina sódica, têm sido empregados para aumentar o desempenho animal a partir da manipulação da fermentação ruminal, pois têm ação bastante similar à do óleo de soja no rúmen, alterando as proporções molares de propionato e acetato e aumentando a eficiência energética ruminal em torno de $5 \%$, em virtude da menor formação de metano (Nagaraja et al., 1997).

$\mathrm{O}$ efeito da adição simultânea de ionóforos e gorduras na alimentação de ruminantes tem sido pouco estudado e parece ser dependente da fonte de gordura e do ionóforo utilizado. Clary et al. (1993) observaram que a lasalocida associada com $4,0 \%$ de sebo bovino reduziu o consumo de matéria seca, indicando haver efeito sinérgico entre gordura e ionóforo. A proporção entre os AGV também foi alterada, com redução de acetato e elevação de propionato, no entanto, sem apresentar interação entre os tratamentos. Zinn (1988) não constatou interação entre graxa amarela (resíduo de gordura de restaurantes) e monensina sobre o desempenho animal, mas os produtos finais da fermentação ruminal foram alterados. Cant et al. (1997) registraram efeito sinérgico entre monensina e óleo de peixe ao reduzir o consumo por vacas lactantes.

Em experimentos in vitro, Lana \& Russel (1996) notaram que a presença de óleo de milho na dieta aumentou a resistência à depleção do potássio intracelular das bactérias ruminais, quando posteriormente foram expostas à ação da monensina e lasalocida. Isto indica que a população selecionada pelo óleo seria semelhante àquela selecionada pelos ionóforos, o que pode explicar os poucos efeitos associados entre óleo e ionóforos reportados na literatura. Nesse sentido, Clary et al. (1993) acreditam que a presença de gordura elevou em três vezes a resistência das bactérias ruminais à lasalocida. De outra forma, a distribuição irregular da gordura dietética no rúmen poderia influenciar a exposição dos microrganismos sensíveis aos ionóforos, afetando a atividade deste aditivo.

No Brasil, o custo da suplementação com óleos vegetais tem limitado seu uso. Entretanto, parte dos pesquisadores tem voltado sua atenção no intuito de fornecer lipídios visando alterar a composição dos ácidos graxos do leite (Cant et al., 1997), aumentando a insaturação da gordura e os níveis de ácido linoléico conjugado (CLA), mediante o uso de fontes insaturadas e sua exposição à bio-hidrogenação no rúmen. Como ambos têm apresentado efeitos sobre a população microbiana e a atividade dos microrganismos, pode-se esperar efeitos diferenciados sobre os parâmetros ruminais e a digestibilidade de nutrientes, com conseqüências no consumo de energia.

Este trabalho foi conduzido com o objetivo de avaliar os efeitos da adição de monensina e de óleo de soja na dieta sobre o consumo, a digestibilidade total e parcial dos nutrientes e os padrões de fermentação ruminal em vacas lactantes.

\section{Material e métodos}

O experimento foi conduzido no Campo Experimental de Coronel Pacheco - EMBRAPA Gado de Leite, no período de agosto a novembro de 2002. As análises laboratoriais foram realizadas no Laborató- 
rio de Nutrição Animal do Departamento de Zootecnia da Universidade Federal de Viçosa.

Quatro vacas 7/8 Holandês-Gir multíparas (155 dias em lactação e peso vivo de $591 \mathrm{~kg}$ ), com cânulas ruminais implantadas, foram dispostas em um quadrado latino $(4 \times 4)$, em arranjo fatorial $2 \times 2$ : presença ou não de monensina sódica (33 ppm) e presença ou não de óleo de soja (4,0\% da MS). Os tratamentos foram assim representados: a) dieta sem óleo e sem monensina: óleo (-) mon (-); b) sem óleo, com monensina: óleo (-) mon (+); c) com óleo, sem monensina: óleo (+) mon (-); d) com óleo, com monensina: óleo (+) mon $(+)$.

As dietas foram formuladas para atender ou exceder as recomendações do NRC (2001) para vacas produzindo acima de $25 \mathrm{~kg}$ de leite por dia. A proporção dos ingredientes e a composição químico-bromatológica das dietas estão apresentadas na Tabela 1. Em média, a alimentação foi composta por $54,8 \%$ de silagem de milho e $45,2 \%$ de concentrado, totalizando $37,0 \%$ de FDN, $21,3 \%$ de FDA e $16,9 \%$ de PB. As dietas sem óleo continham 2,44\% de EE e as dietas com óleo, $6,19 \%$. Tanto o óleo de soja como a monensina (Rumensin ${ }^{\circledR}$, Elanco CO.) foram adicionados ao concentrado em seus respectivos tratamentos.

Os animais foram mantidos em confinamento e foram alimentados duas vezes ao dia ( $8 \mathrm{~h}$ e $15 \mathrm{~h} 30) \mathrm{em}$ igual proporção, sendo a alimentação fornecida individualmente em cochos com controle eletrônico individual tipo "Calan Gate" (Calan Data Ranger®). As sobras foram retiradas e pesadas diariamente no período de coleta, para formação de uma amostra composta, e imediatamente congeladas, para posterior análise. O nível de oferta foi ajustado para se manter $10 \%$ de sobras. Os animais foram ordenhados diariamente às $5 \mathrm{~h}$ e $15 \mathrm{~h}$.

Os animais foram pesados no primeiro e no último dia de cada período experimental, sempre após a ordenha matinal. O período experimental consistiu de 18 dias de adaptação à dieta e três dias de coleta. Para o ensaio de digestibilidade, foram utilizados óxido crômico $\left(\mathrm{Cr}_{2} \mathrm{O}_{3}\right)$ e FDA indigestível (FDAi) como indicadores externo e interno, respectivamente. Dez dias antes do início e durante o período de avaliação, dez gramas de óxido crômico $\left(\mathrm{Cr}_{2} \mathrm{O}_{3}\right)$ foram colocados via cânula ruminal, sempre quatro horas após a alimentação da manhã. Durante o período de avaliação, além da adição de óxido crômico, amostras de fezes foram coletadas na manhã do dia 19 e no início e final da tarde dos dias 20 e 21, sendo
Tabela 1 - Ingredientes e composição química das dietas experimentais

Table 1 - Ingredients and chemical composition of the experimental diets

\begin{tabular}{|c|c|c|}
\hline \multirow[t]{2}{*}{$\begin{array}{l}\text { Ingredientes }^{1} \\
\text { Ingredients }^{1}\end{array}$} & \multicolumn{2}{|c|}{$\begin{array}{l}\text { Dietas } \\
\text { Diets }\end{array}$} \\
\hline & $\begin{array}{l}\text { Sem óleo } \\
\text { Without oil }\end{array}$ & $\begin{array}{l}\text { Com óleo } \\
\text { With oil }\end{array}$ \\
\hline $\begin{array}{l}\text { Silagem de milho } \\
\text { Corn silage }\end{array}$ & 55,11 & 54,52 \\
\hline $\begin{array}{l}\text { Concentrado } \\
\text { Concentrate }\end{array}$ & 44,89 & 45,48 \\
\hline $\begin{array}{l}\text { Núcleo energético protéico } \\
\text { Energy protein nисleo }\end{array}$ & 43,23 & 39,71 \\
\hline $\begin{array}{l}\text { Óleo de soja } \\
\text { Soybean oil }\end{array}$ & - & 3,93 \\
\hline $\begin{array}{l}\text { Uréia } \\
\text { Urea }\end{array}$ & 0,53 & 0,86 \\
\hline $\begin{array}{l}\text { Sulfato de amônia } \\
\text { Ammonium sulphate }\end{array}$ & 0,06 & 0,10 \\
\hline $\begin{array}{l}\text { Sal comum } \\
\text { Salt }\end{array}$ & 0,32 & 0,30 \\
\hline $\begin{array}{l}\text { Calcário calcítico } \\
\text { Calcitic limestone }\end{array}$ & 0,14 & 0,11 \\
\hline $\begin{array}{l}\text { Fosfato bicálcico } \\
\text { Dicalcium phosphate }\end{array}$ & 0,53 & 0,49 \\
\hline $\begin{array}{l}\text { Suplemento mineral } \\
\text { Mineral premix } \\
\text { Composição química, \% } \\
\text { Chemical composition, \% }\end{array}$ & 0,08 & 0,07 \\
\hline $\begin{array}{l}\text { Matéria orgânica } \\
\text { Organic matter }\end{array}$ & 90,90 & 94,12 \\
\hline $\begin{array}{l}\text { FDN } \\
N D F\end{array}$ & 37,35 & 36,74 \\
\hline $\begin{array}{l}\text { FDA } \\
A D F\end{array}$ & 21,31 & 21,32 \\
\hline $\begin{array}{l}\text { Proteína bruta } \\
\text { Crude protein }\end{array}$ & 16,48 & 16,12 \\
\hline $\begin{array}{l}\text { Extrato etéreo } \\
\text { Ether extract }\end{array}$ & 2,44 & 6,19 \\
\hline
\end{tabular}

${ }^{1}$ Nos tratamentos com monensina sódica: 33 ppm no concentrado.

1 Treatments with sodium monensin, $33 \mathrm{ppm}$ at concentrate.

homogeneizadas, para compor uma amostra composta, e, posteriormente, congeladas.

Nos dois últimos dias do período experimental foram coletadas amostras de digesta omasal, de acordo com Leão et al. (2004), em horários intercalados de três em três horas até perfazerem a avaliação de 24 horas do dia. As coletas foram realizadas nos seguintes horários: às $8 \mathrm{~h}$ (antes da alimentação), $14 ; 20 ; 2 ; 5 ; 11 ; 17$; e $23 \mathrm{~h}$. Estas amostras foram secas em estufa de ventilação forçada $\left(60^{\circ} \mathrm{C}\right)$, pro-

R. Bras. Zootec., v.34, n.1, p.297-308, 2005 
cessadas em moinho de bola, homogeneizadas, retirando-se uma alíquota de cada tempo de coleta para formar uma amostra composta por dia.

Nas amostras de alimento oferecido, sobras, digesta omasal e fezes foram determinados os teores de matéria seca (MS), matéria orgânica (MO), nitrogênio total (Kjeldahl), cinzas e extrato etéreo (EE) no aparelho Soxhlet, de acordo com Silva \& Queiroz (2002). O teor de proteína bruta (PB) foi obtido pela multiplicação do teor de nitrogênio total por 6,25. Os teores de fibra em detergente neutro (FDN) e fibra em detergente ácido (FDA) foram estimados segundo Van Soest et al. (1991), utilizando-se $\alpha$-amilase e sem a adição de sulfito de sódio na determinação do FDN. Em função da baixa recuperação do resíduo do extrato etéreo das amostras de digesta omasal, adotou-se a técnica modificada e descrita por Sukhija \& Palmquist (1988), empregando-se uma mistura de $10 \%$ de ácido acético glacial, $45 \%$ de éter etílico e 45\% de éter de petróleo como solventes no aparelho Soxhlet. A quantificação de cromo nas fezes foi realizada de acordo com a técnica de Williams et al. (1962), descrita por Silva \& Queiroz (2002).

Para determinação do FDAi, as amostras dos alimentos ofertados, das sobras, das fezes e da digesta de omaso foram incubadas por 144 horas no rúmen de vacas alimentadas com relação 60:40 de volumoso e concentrado, em sacos Ankom (Ankom ${ }^{\circledR}$ filter bag n ${ }^{\circ} 57$ ), segundo adaptação da técnica descrita por Cochran et al. (1986). O resíduo da incubação presente nos sacos Ankom foi submetido à extração com detergente ácido, lavado em água destilada fervente e acetona, e, após a secagem definitiva, o material resultante foi considerado como FDAi.

Os teores de carboidratos totais (CHO) foram obtidos a partir da equação sugerida por Sniffen et al. (1992), em que $\mathrm{CHO}=100-(\% \mathrm{~PB}+\% \mathrm{EE}+$ \%Cinzas), enquanto os carboidratos não-fibrosos (CNF), pela diferença entre $\mathrm{CHO}$ e FDN.

Para determinação da concentração de nitrogênio amoniacal $\left(\mathrm{N}_{-} \mathrm{NH}_{3}\right)$, pHe AGV do líquido ruminal, foram obtidas amostras, manualmente, em cinco pontos diferentes do rúmen, que foram filtradas em pano de algodão. As coletas de líquido de rúmen foram simultâneas às coletas de digesta omasal. Para a leitura imediata do $\mathrm{pH}$ do líquido ruminal, utilizou-se um potenciômetro portátil. Nas amostras do líquido ruminal para a análise de $\mathrm{AGV}$, foram adicionados $1,0 \mathrm{~mL}$ de ácido meta-fosfórico a $25 \%$ para cada
$5,0 \mathrm{~mL}$ de líquido ruminal coletados. Amostraram-se 10,0 mL de líquido ruminal para determinação da concentração de amônia. As amostras foram imediatamente congeladas após a coleta. No laboratório, alíquotas de 2,0 $\mathrm{mL}$ de todas as amostras de líquido ruminal foram transferidas para tubos eppendorf e centrifugadas duas vezes por 15 minutos a $12.500 \mathrm{~g}$. A concentração de amônia foi quantificada pelo método colorimétrico de Chaney \& Marbach (1962). Os AGV foram determinados em um cromatógrafo HPLC marca HP-1050, provido de um integrador HP-1047A e de coluna de sílica fundida de $300 \mathrm{~mm}$ x 7,8 $\mathrm{mm}$. O tempo de corrida foi de 20 minutos.

A estimativa da síntese microbiana foi realizada a partir da quantificação dos derivados de purina excretados na urina e no leite, de acordo com Valadares et al. (1999) e Rennó (2003), considerando-se a absorção de purinas (Pabs) a partir da fórmula sugerida por Verbic et al. (1990): Pabs $=0,85 \mathrm{X}+0,385 \mathrm{PV}^{0,75}$, em que $\mathrm{X}$ é excreção total dos derivados de purina. A amostra de urina foi obtida por micção espontânea, quatro horas após a alimentação dos animais, coletando-se $10 \mathrm{~mL}$ de urina, e adicionados $40 \mathrm{~mL}$ de ácido sulfúrico 0,036 N. Nesta amostra foi determinada a concentração de alantoína a partir dos métodos colorimétricos descritos por Chen \& Gomes (1992), e a concentração de ácido úrico e de creatinina, utilizando-se "kits" comerciais (Labtest $\left.{ }^{\circledR}\right)$. O volume urinário foi determinado pela concentração de creatinina na urina, considerando-se excreção diária de $28,9 \mathrm{mg} / \mathrm{kgPV} /$ dia, observados por Valadares et al. (1999).

Os dados foram submetidos à análise de variância, segundo o modelo:

$$
Y_{i j k l}=\mu+M_{i}+O_{j}+O M_{i j}+V_{k}+P_{l}+\tilde{n}_{i j k l}
$$

em que $\mathrm{Y}_{\mathrm{ijkl}}$ é a variável dependente; $\mu$, a média das

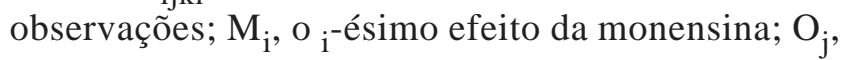
$\mathrm{o}_{\mathrm{j}}$-ésimo efeito do óleo; $\mathrm{OM}_{\mathrm{ij}}$, $\mathrm{o}_{\mathrm{ij}}$-ésimo efeito da interação; $\mathrm{V}_{\mathrm{k}}, \mathrm{o}_{\mathrm{k}}$-ésimo efeito da vaca; $\mathrm{P}_{1}, \mathrm{o}_{1}$-ésimo efeito do período; e $\hat{A}_{\mathrm{ijk} 1}$ o erro experimental. Os cálculos foram realizados com o auxílio do programa SAS (1997). A análise estatística das variáveis $\mathrm{pH}$ e $\mathrm{N}-\mathrm{NH}_{3}$ foi realizada por meio de estudos de regressão e comparação de médias, incluindo-se no modelo os efeitos da regressão, dos tempos de coleta e da interação tempo de coleta e tratamentos. 


\section{Resultados}

Não foi verificada alteração de peso $(\mathrm{P}<0,05)$ entre os animais em relação aos tratamentos (Tabela 2). $\mathrm{Na}$ Tabela 2, constam os resultados médios dos consumos de MS e de FDN, em quilogramas e em relação ao peso vivo, o consumo de NDT e da produção de leite (PL). Não foi verificada interação entre óleo e monensina e efeito da monensina sobre estas variáveis $(\mathrm{P}>0,05)$. A presença de óleo de soja na dieta reduziu o CMS, CMSP e CMSTM, em média, em $13,8 \%$, corroborando as indicações do NRC (2001), em que a adição de lipídios pode limitar o consumo por efeitos sobre a fermentação ruminal ou efeitos de ordem metabólica.

O consumo de NDT não foi influenciado $(\mathrm{P}>0,05)$ pelos tratamentos, embora a combinação de óleo de soja e de monensina tenha propiciado redução de 6,97\% no consumo de NDT em relação à dieta com ausência destes ingredientes. A adição de lipídios inibiu o CFDN e CFDNP em 18,7 e 18,3\%, respectivamente. Da mesma forma, a produção de leite foi reduzida em $11,6 \%$ pela presença de óleo.

$\mathrm{Na}$ Tabela 3, encontram-se as médias das digestibilidades aparentes totais e parciais da MS, MO, PB, EE, FDN, CNF e CHO. Os diferentes indicadores utilizados não diferiram entre si para a estimativa da produção fecal, sendo de 4,77 e $4,75 \mathrm{~kg} /$ dia $(\mathrm{DP}=0,172 ; \mathrm{P}=0,9415)$ para $\mathrm{Cr}_{2} \mathrm{O}_{3}$ e FDAi, respectivamente. Estes resultados estão de acordo com os observados por Rennó (2003), que recomenda o FDAi como indicador para estimar o fluxo de matéria seca no abomaso e nas fezes. Desta forma, os resultados observados para digestibilidade aparente total e ruminal foram obtidos utilizando-se FDAi como indicador interno.

A digestibilidade aparente total dos nutrientes não foi influenciada pelo óleo de soja ou pela monensina e não foi observada interação significativa entre estes tratamentos $(\mathrm{P}>0,05)$ para as digestibilidades aparentes da MS, MO, FDN, PB, CNF e CHT. Verificou-se efeito de óleo $(\mathrm{P}=0,0006)$ sobre a digestibilidade aparente total do EE, que foi maior na presença de óleo de soja (86,18 vs. 77,06\%; DP=1,06). Embora a técnica de estimativa dos ácidos graxos pela extração em éter seja imprecisa, por haver contaminação de outras substâncias solúveis em éter, como ceras e pigmentos (Van Soest, 1994), a maior digestibilidade verificada na presença de óleo pode ser atribuída ao efeito de diluição destas substâncias e à maior digestibilidade dos ácidos graxos pela ação do ácido oléico ao solubilizar os sabões de cálcio da

Tabela 2 - Peso vivo dos animais (PV), consumo de matéria seca por dia (CMS), por $100 \mathrm{~kg}$ de PV (CMSP) e por unidade de tamanho metabólico (CMSTM), teor e consumo de NDT (CNDT), consumo de FDN diário e por $100 \mathrm{~kg}$ de PV (CFDN e CFDNP) e produção de leite (PL) de vacas alimentadas com dietas contendo combinação de óleo de soja e monensina

Table 2 - Live weight of animals (LW), daily dry matter intake (DMI), in relation at live weight (DMIP) and metabolic weight (DMIMW), content and TDN daily intake, FDN daily intake and in relation at live weight (CNDF and CNDFP) and milk production (MP) of lactating dairy cows fed diets with monensin and soybean oil combination

\begin{tabular}{|c|c|c|c|c|c|c|c|c|c|}
\hline \multirow[t]{2}{*}{$\begin{array}{l}\text { Itens } \\
\text { Items }\end{array}$} & \multicolumn{4}{|c|}{$\begin{array}{l}\text { Médias dos tratamentos } \\
\text { Treatments means }\end{array}$} & \multirow{2}{*}{$\begin{array}{c}\text { Desvio- } \\
\text { padrão } \\
\text { Standard error }\end{array}$} & \multicolumn{2}{|c|}{$\begin{array}{l}\text { Efeitos óleo } \\
\text { Oil effects }\end{array}$} & \multicolumn{2}{|c|}{$\begin{array}{l}\text { Médias óleo } \\
\text { Oil means }\end{array}$} \\
\hline & $\begin{array}{l}\text { mon }(-) \\
\text { óleo }(-)\end{array}$ & $\begin{array}{l}\text { mon }(+) \\
\text { óleo }(-)\end{array}$ & $\begin{array}{l}\text { mon (-) } \\
\text { óleo (+) }\end{array}$ & $\begin{array}{l}\text { mon }(+) \\
\text { óleo }(+)\end{array}$ & & $\mathrm{P}>\mathrm{F}$ & $\mathrm{DP}$ & $\begin{array}{c}\text { Sem } \\
\text { Without }\end{array}$ & $\begin{array}{l}\text { Com } \\
\text { With }\end{array}$ \\
\hline $\mathrm{PV}(L W)$ & 594,2 & 591,5 & 591,4 & 590,0 & 2,40 & Ns & - & - & - \\
\hline $\mathrm{CMS}^{1}(D M I)$ & 17,8 & 17,2 & 15,3 & 14,7 & 0,560 & 0,006 & 0,396 & $17,5^{\mathrm{a}}$ & $15,1^{\mathrm{b}}$ \\
\hline $\operatorname{CMSP}^{2}(D M I P)$ & 3,02 & 2,96 & 2,64 & 2,52 & 0,095 & 0,005 & 0,068 & $2,99^{a}$ & $2,58^{\mathrm{b}}$ \\
\hline $\operatorname{CMSTM}^{3}($ DMIMW) & 0,149 & 0,145 & 0,130 & 0,124 & 0,005 & 0,003 & 0,003 & $0,147^{\mathrm{a}}$ & $0,127^{b}$ \\
\hline $\mathrm{NDT}^{4}(T N D)$ & 66,2 & 67,5 & 76,0 & 74,0 & 1,057 & 0,0002 & 0,075 & $66,7^{\mathrm{a}}$ & $75,3^{\mathrm{b}}$ \\
\hline $\mathrm{CNDT}^{1}(T N D I)$ & 11,76 & 11,56 & 11,83 & 10,94 & 0,327 & $\mathrm{~ns}$ & - & - & - \\
\hline $\mathrm{CFDN}^{1}(N D F I)$ & 6,55 & 6,49 & 5,54 & 5,19 & 0,192 & 0,001 & 0,135 & $6,52^{\mathrm{a}}$ & $5,37^{\mathrm{b}}$ \\
\hline $\mathrm{CFDNP}^{2}(N D F P)$ & 1,114 & 1,113 & 0,936 & 0,886 & 0,036 & 0,013 & 0,025 & $1,114^{\mathrm{a}}$ & $0,911^{\mathrm{b}}$ \\
\hline $\mathrm{PL}^{1}(M P)$ & 22,4 & 22,5 & 20,3 & 19,2 & 0,596 & 0,0042 & 0,421 & $22,4^{\mathrm{a}}$ & $19,8^{\mathrm{b}}$ \\
\hline
\end{tabular}

$1 \mathrm{~kg} / \mathrm{dia}(\mathrm{kg} / \mathrm{day}) ;{ }^{2} \mathrm{~kg} / 100 \mathrm{~kg} \mathrm{PV}(\mathrm{kg} / 100 \mathrm{~kg} L W) ;{ }^{3} \mathrm{~kg} / \mathrm{PV} 0,75\left(\mathrm{~kg} / \mathrm{LW}{ }^{0.75}\right) ;{ }^{4} \mathrm{NDT}=\mathrm{CNDT} / \mathrm{CMS}(\%) ;(N D T=T N D I / D M I, \%)$.

a, b Letras diferentes na mesma linha diferem, Tukey $(\mathrm{P}<0,05)$; ns - não-significativo.

$a, b$ Different letters in same row differ, Tukey $(P<.05) ; n s-$ not significant.

R. Bras. Zootec., v.34, n.1, p.297-308, 2005 
Tabela 3 - Valores médios da digestibilidade aparente total e ruminal da matéria seca (MS), matéria orgânica (MO), proteína bruta (PB), extrato etéreo (EE), fibra em detergente neutro (FDN), carboidratos não-fibrosos (CNF) e carboidratos totais $(\mathrm{CHO})$ das dietas de vacas alimentadas com a combinação de óleo e monensina

Table 3 - Mean values of apparent digestibility of total and ruminal digestibility of dry matter (DM), organic matter (OM), crude protein (CP), ether extract (EE), neutral detergent fiber (NDF), nonfiber carbohydrates (NFC) and total carbohydrates (TCHO) of lactating dairy cows fed diets with monensin and soybean oil combination

\begin{tabular}{|c|c|c|c|c|c|}
\hline \multirow[t]{2}{*}{$\begin{array}{l}\text { Variáveis } \\
\text { Variables }\end{array}$} & \multicolumn{4}{|c|}{$\begin{array}{l}\text { Tratamentos } \\
\text { Treatments }\end{array}$} & \multirow[t]{2}{*}{$\begin{array}{c}\text { Desvio- padrão } \\
\text { Standard error }\end{array}$} \\
\hline & mon (-)óleo (-) & mon (+)óleo (-) & mon (-)óleo (+) & mon (+)óleo (+) & \\
\hline & \multicolumn{5}{|c|}{$\begin{array}{c}\text { Digestibilidade total (\%) } \\
\text { Total digestibility }\end{array}$} \\
\hline $\operatorname{MS}(D M)$ & 69,87 & 71,75 & 72,34 & 70,02 & 1,26 \\
\hline $\mathrm{MO}(O M)$ & 70,71 & 72,09 & 73,60 & 71,37 & 1,17 \\
\hline $\mathrm{PB}(C P)$ & 74,26 & 76,35 & 76,83 & 75,90 & 0,78 \\
\hline $\mathrm{EE}^{2}$ & 75,35 & 78,77 & 86,63 & 87,01 & 1,50 \\
\hline $\mathrm{FDN}(N D F)$ & 54,74 & 56,80 & 55,01 & 52,98 & 1,74 \\
\hline $\mathrm{CNF}(N F C)$ & 85,68 & 86,30 & 87,84 & 84,22 & 1,48 \\
\hline $\mathrm{CHT}(\mathrm{TCHO})$ & 69,70 & 70,85 & 71,46 & 68,94 & 1,28 \\
\hline
\end{tabular}

\begin{tabular}{|c|c|c|c|c|c|}
\hline \multirow[b]{2}{*}{$\operatorname{MS}(D M)$} & \multicolumn{5}{|c|}{$\begin{array}{l}\text { Digestibilidade ruminal, } \% 1 \\
\text { Ruminal digestibility }\end{array}$} \\
\hline & 41,00 & 44,56 & 43,66 & 41,43 & 1,61 \\
\hline $\mathrm{MO}(O M)$ & 50,65 & 52,97 & 54,42 & 51,78 & 1,56 \\
\hline $\mathrm{PB}(C P)$ & 30,82 & 31,79 & 31,86 & 32,01 & 2,24 \\
\hline $\mathrm{EE}$ & 6,01 & 9,90 & 12,50 & 7,85 & 4,56 \\
\hline $\mathrm{CNF}^{3}(N F C)$ & 70,93 & 74,34 & 81,59 & 80,32 & 2,92 \\
\hline $\mathrm{CHT}(\mathrm{TCHO})$ & 50,48 & 53,05 & 53,48 & 51,68 & 1,14 \\
\hline
\end{tabular}

$1 \%$ em função do total ingerido (\% in function of total intake).

${ }^{2}$ Efeito óleo $(P=0,0006)$ (oil effect, $\left.P=.0006\right)$.

${ }^{3}$ Efeito óleo ( $\left.P=0,0006\right)$ (oil effect, $P=.0006$ ).

digesta, auxiliando os sais biliares na formação da micela (Palmquist, 1994).

A digestibilidade aparente ruminal da MS, MO, $\mathrm{PB}, \mathrm{EE}$ e CHT não foi influenciada pelos tratamentos. A digestibilidade ruminal dos CNF foi maior na presença de óleo de soja (86,96 vs. 72,63\%; DP=2,03), indicando que houve proporcionalmente maior digestão intestinal do CNF nas distas sem óleo, possivelmente em função do maior CMS.

Observou-se interação significativa $(\mathrm{P}=0,0335)$ entre óleo de soja e monensina sobre a digestibilidade da FDN no rúmen (Tabela 4), embora a digestibilidade total da FDN tenha sido similar entre os tratamentos, refletindo compensação sobre a digestão da FDN nos outros compartimentos do trato gastrintestinal (Bateman \& Jenkins, 1998). A digestibilidade ruminal da FDN não diferiu com a presença ou ausência de óleo quando não havia monensina na dieta. Quando na presença de monensina, o óleo de soja reduziu a digestibilidade ruminal da FDN de 45,71 para 39,75\%. Nas dietas sem óleo, a monensina elevou a digestibilidade da fibra $(43,68$ vs $45,71 \%$ ), enquanto, nas dietas com óleo, reduziu a digestibilidade deste nutriente (45,08 vs 39,75\%).
Na Figura 1, encontram-se os valores médios do $\mathrm{pH}$ ruminal em função dos tempos de coleta. $\mathrm{O}$ pH ruminal não foi influenciado pela presença de monensina ou óleo na dieta, sendo 6,35, em média

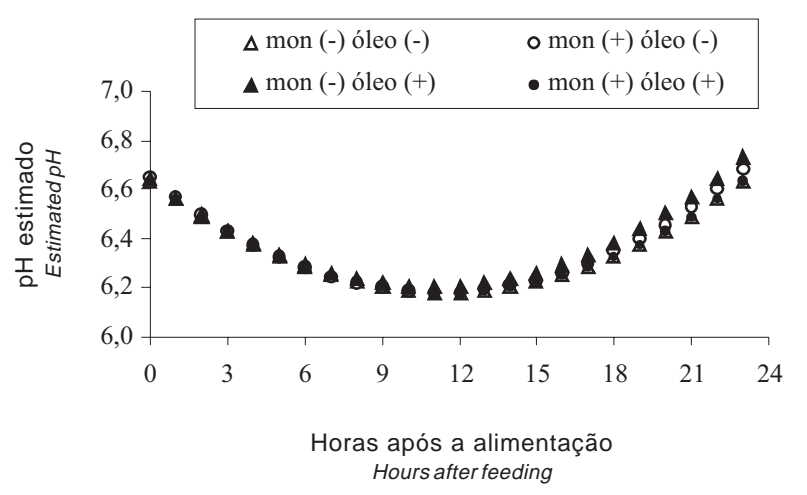

Figura 1 - Variação diária do pH ruminal em função do tempo ( $T$, em horas) após a alimentação da manhã $\left(\mathrm{pH}=6,62-0,071 \mathrm{~T}+0,003 \mathrm{~T}^{2}\right.$, $\left.\mathrm{CV}=2,45 ; r^{2}=0,4457\right)$

Figure 1 - Daily variation of rumen $\mathrm{pH}$ in function of time after morning feeding $(T$, in hours; $p H=6.62-$ $\left.0.071 T+0.003 T^{2} . C V=2.45 ; r^{2}=0.4457\right)$. 
Tabela 4 - Valores médios observados para a interação entre óleo de soja e monensina sobre a digestibilidade ruminal aparente da FDN

Table 4 - Medium observed values for soybean oil and monensin interaction on NDF apparent ruminal digestibility

\begin{tabular}{|c|c|c|}
\hline & $\begin{array}{l}\text { Sem monensina } \\
\text { Without monensin }\end{array}$ & $\begin{array}{c}\text { Com monensina } \\
\text { With monensin }\end{array}$ \\
\hline Sem óleo (Without oil) & $43,68^{\mathrm{Aa}}$ & $45,71^{\mathrm{Ab}}$ \\
\hline Com óleo (With oil) & $45,08^{\mathrm{Aa}}$ & $39,75^{\mathrm{Bb}}$ \\
\hline
\end{tabular}

$A, B$ Letras diferentes na mesma coluna diferem, Tukey $(P<0,05)$.

$A, B$ Different letters in same column differ, Tukey $(P<.05)$.

$a, b$ Letras diferentes na mesma linha diferem, Tukey $(P<0,05)$.

$a, b$ Different letters in same row differ, Tukey $(P<.05)$.

(Tabela 5). O modelo matemático que melhor descreveu o $\mathrm{pH}$ ruminal ao longo do dia foi: $\mathrm{pH}=6,62-$ $0,071 \mathrm{~T}+0,003 \mathrm{~T}^{2}$, em que T é o tempo após a alimentação da manhã, expresso em horas. O pH mínimo calculado foi de 6,2 para as 11,8 horas após a alimentação (Figura 1).

Observou-se interação significativa entre óleo e monensina sobre a concentração de $\mathrm{N}-\mathrm{NH}_{3}$ no rúmen ( $\mathrm{P}=0,048)$. A distribuição diária das concentrações estimadas em relação ao tempo após a alimentação da manhã, está representada na Figura 2. Na Tabela 6, encontram-se as médias da concentração de nitrogênio amoniacal e a interação entre os tratamentos. $\mathrm{O}$ óleo de soja reduziu a concentração de nitrogênio amoniacal tanto na ausência (12,30 vs 9,41 mg/dL) como na presença de monensina na dieta $(11,66$ vs $10,79 \mathrm{mg} / \mathrm{dL}$ ). Por outro lado, enquanto a monensina reduziu a concentração de nitrogênio amoniacal nas dietas sem óleo (12,30 vs 11,66 mg/dL), o óleo elevou a concentração a de 9,41 para $10,79 \mathrm{mg} / \mathrm{dL}$.

Os AGV totais não foram influenciados pelos tratamentos, com média de 99,43 mM (Tabela 5). Isoladamente, tanto o óleo como a monensina aumentaram as proporções molares de propionato e reduziram a relação acetato propionato (A:P). A proporção de butirato não foi influenciada pela monensina, mas foi reduzida com a adição de óleo de soja. A proporção de acetato foi reduzida tanto pelo óleo quanto pela monensina, verificando-se efeito de interação entre os tratamentos com $\mathrm{P}=0,1044$ (Tabela 6). $\mathrm{Na}$ interação, a monensina reduziu as concentrações de acetato quando o óleo esteve presente ou ausente na dieta. Na ausência de monensina, o óleo de soja reduziu a concentração de acetato, mas não alterou a concentração de acetato quando em combinação com monensina.

A síntese de nitrogênio microbiano foi influenciada pela monensina $(\mathrm{P}=0,0302)$, pelo óleo $(\mathrm{P}=0,0005)$,

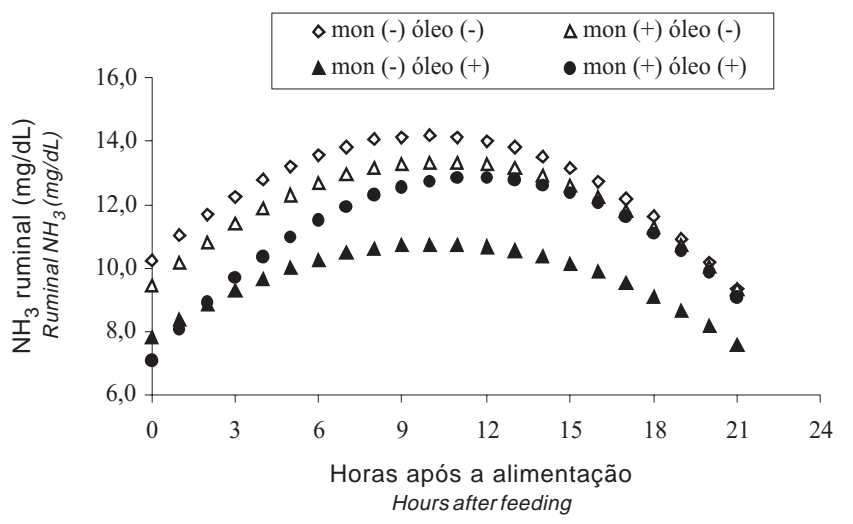

Figura 2 - Variação diária das concentrações ruminais de N-NH${ }_{3}$ em função do tempo após a alimentação da manhã ( $T$, em horas).

Figure 2 - Daily variation of $\mathrm{N}-\mathrm{NH}_{3}$ rumen concentration in function of time after morning feeding ( $T$, in hours).

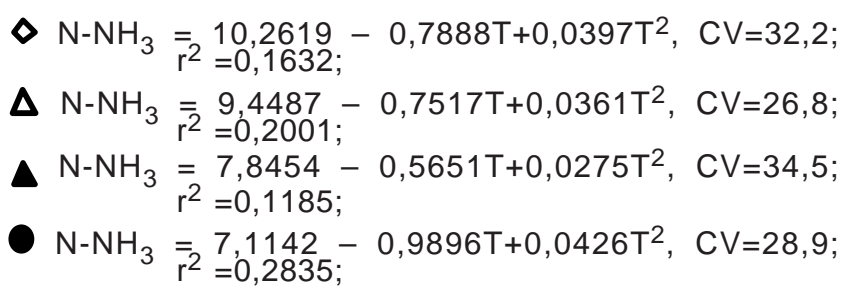

havendo interação entre estes tratamentos $(\mathrm{P}=0,1016)$ (Tabela 6). Na interação, a presença de óleo inibiu a síntese microbiana tanto nas dietas com (227,1 vs $178,6 \mathrm{~g} / \mathrm{dia})$ ou sem monensina (231,9 vs 203,1 g/dia). Nas dietas sem óleo, a síntese microbiana não foi influenciada pela monensina, mas nas dietas com óleo e monensina foi reduzida de 203,1 para 178,6 g/dia.

Embora os tratamentos tenham influenciado a síntese de nitrogênio microbiano (Nmic), a eficiência de síntese microbiana (EfSM), expressa em gramas de nitrogênio por unidade de matéria orgânica degradada no rúmen ( $\mathrm{g} \mathrm{N} / \mathrm{kg}$ MODR), não foi influenciada pelos tratamentos, observando-se, em média, 24,89 g N/kg MODR. 
Tabela 5 - Efeitos de dietas contendo a combinação de monensina e óleo de soja sobre o pH ruminal, a concentração de nitrogênio amoniacal $\left(\mathrm{N}-\mathrm{NH}_{3}\right)$ e de ácidos graxos voláteis (AGV) no líquido de rúmen, proporção molar de acetato $(A)$, propionato $(P)$ e butirato $(B)$, e relação acetato:propionato no total de $A G V$, síntese de nitrogênio microbiano (NMic) e eficiência de síntese microbiana (EfSM)

Table 5 - Effects of diets contained monensin (Mon) and soybean oil (Oil) combination on rumen $\mathrm{pH}, \mathrm{N}-\mathrm{NH}_{3}$ and volatile fatty acids $(V F A)$ in rumen liquor, molar proportion of acetic acid $(A)$, propionic acid $(P)$ and butyric acid, acetate:propionate ration $(A: P)$, microbial nitrogen synthesis (NMic) and efficiency of microbial synthesis (EfSM)

\begin{tabular}{|c|c|c|c|c|c|c|c|c|c|c|c|c|}
\hline \multirow[t]{2}{*}{$\begin{array}{l}\text { Itens } \\
\text { Items }\end{array}$} & \multicolumn{4}{|c|}{$\begin{array}{c}\text { Médias dos tratamentos } \\
\text { Treatments means }\end{array}$} & \multirow[t]{2}{*}{$\begin{array}{c}\mathrm{DPM}^{1} \\
S E M\end{array}$} & \multicolumn{3}{|c|}{$\begin{array}{l}\text { Efeitos }(\mathrm{P}>\mathrm{F}) \\
\text { Effects }(P>F)\end{array}$} & \multicolumn{2}{|c|}{$\begin{array}{l}\text { Médias monesina }{ }^{1} \\
\text { Monensim means }\end{array}$} & \multicolumn{2}{|c|}{$\begin{array}{c}\text { Médias óleo } \\
\text { Oil means }\end{array}$} \\
\hline & $\begin{array}{l}\text { mon }(-) \\
\text { óleo }(-)\end{array}$ & $\begin{array}{l}\text { mon }(+) \\
\text { óleo }(-)\end{array}$ & $\begin{array}{l}\text { mon }(-) \\
\text { óleo }(+)\end{array}$ & $\begin{array}{l}\text { mon }(+) \\
\text { óleo }(+)\end{array}$ & & Mon & Óleo & $\mathrm{M}^{*} \mathrm{O}$ & $\begin{array}{c}\text { Sem } \\
\text { Without }\end{array}$ & $\begin{array}{l}\text { Com } \\
\text { With }\end{array}$ & $\begin{array}{c}\text { Sem } \\
\text { Without }\end{array}$ & $\begin{array}{l}\text { Com } \\
\text { With }\end{array}$ \\
\hline $\mathrm{pH}$ & 6,34 & 6,35 & 6,38 & 6,35 & 0,12 & $\mathrm{~ns}$ & $\mathrm{~ns}$ & $\mathrm{~ns}$ & - & - & - & - \\
\hline $\mathrm{N}-\mathrm{NH}_{3}, \mathrm{mg} / \mathrm{dL}$ & 12,30 & 11,66 & 9,41 & 10,79 & 0,512 & $\mathrm{~ns}$ & 0,0003 & 0,048 & - & - & - & - \\
\hline $\mathrm{AGV}, \mathrm{mM}$ & 106,6 & 97,8 & 100,5 & 92,8 & 7,663 & $\mathrm{~ns}$ & $\mathrm{~ns}$ & $\mathrm{~ns}$ & - & - & - & - \\
\hline
\end{tabular}

$V F A, m M$

Proporção molar de ácidos graxos, $\mathrm{mMol} \%$ Molar proportion of fatty acids, $\mathrm{mMol} \%$

\begin{tabular}{|c|c|c|c|c|c|c|c|c|c|c|c|c|}
\hline Acetato (A) & 71,7 & 67,9 & 69,4 & 67,7 & 0,573 & 0,0033 & 0,0670 & 0,104 & - & - & - & - \\
\hline $\begin{array}{l}\text { Acetate } \\
\text { Propionato }(\mathrm{P})\end{array}$ & 22,4 & 25,5 & 25,3 & 26,8 & 0,834 & 0,0337 & 0,0430 & $\mathrm{~ns}$ & $23,8^{\mathrm{A}}$ & $26,1^{\mathrm{B}}$ & $23,9^{\mathrm{a}}$ & $26,0^{b}$ \\
\hline $\begin{array}{l}\text { Propionate } \\
\text { Butirato }\end{array}$ & 5,90 & 6,60 & 5,32 & 5,46 & 0,318 & $\mathrm{~ns}$ & 0,0356 & $\mathrm{~ns}$ & - & - & $6,25^{\mathrm{a}}$ & $5,39^{\mathrm{b}}$ \\
\hline $\begin{array}{l}\text { Butyrate } \\
\text { Rel. A:P } \\
\text { A.P ratio }\end{array}$ & 3,21 & 2,70 & 2,79 & 2,56 & 0,103 & 0,0115 & 0,0338 & $\mathrm{~ns}$ & $3,00^{\mathrm{A}}$ & $2,63^{\mathrm{B}}$ & $2,96^{\mathrm{a}}$ & $2,68^{b}$ \\
\hline & & & & & $\begin{array}{l}\text { Sín } \\
\text { Mic }\end{array}$ & $\begin{array}{l}\text { tese mi } \\
\text { robials }\end{array}$ & $\begin{array}{l}\text { robiana } \\
\text { nthesis }\end{array}$ & & & & & \\
\hline $\begin{array}{l}\text { NMic, g/dia } \\
\text { Nmic, g/day }\end{array}$ & 231,9 & 227,1 & 203,1 & 178,6 & 4,534 & 0,0302 & 0,0005 & 0,102 & - & - & - & - \\
\hline $\begin{array}{l}\text { EfSM, g N/kg } \\
\text { MODR }\end{array}$ & 25,9 & 26,0 & 24,2 & 25,4 & 0,918 & $\mathrm{~ns}$ & $\mathrm{~ns}$ & $\mathrm{~ns}$ & - & - & - & - \\
\hline
\end{tabular}

$A, B$ Letras diferentes na mesma linha diferem Tukey $(P<0,05)$ (Different letters in same row differ, Tukey, $P<.05)$.

$a, b$ Letras diferentes na mesma linha diferem, Tukey $(P<0,05)$ (Different letters in same row differ, Tukey, $P<.05$ ).

1 DPM - desvio-padrão da média (SEM - Standad error of mean).

Tabela 6 - Médias observadas da interação entre óleo de soja e monensina sobre a concentração de $\mathrm{N}-\mathrm{NH}_{3}$ no rúmen, proporção de acetato no total de AGV e síntese microbiana (Nmic)

Table 6 - Observed means values of soybean oil and monensin interaction on $\mathrm{N}^{-\mathrm{NH}_{3}}$ rumen concentration, acetic proportion on total VFA and ruminal microbial synthesis

\begin{tabular}{lccc}
\hline & $\begin{array}{c}\text { Sem monensina } \\
\text { Without monensin }\end{array}$ & ${\mathrm{N}-N H_{3}, \mathrm{mg} / \mathrm{dL}}$ & $\begin{array}{c}\text { Com monensina } \\
\text { With monensin }\end{array}$ \\
Sem óleo (Without oil) & $12,30^{\mathrm{Aa}}$ & & $11,66^{\mathrm{Ab}}$ \\
Com óleo (With oil) & $9,41^{\mathrm{Ba}}$ & Acetato, mMol \% & $10,79^{\mathrm{Bb}}$ \\
Sem óleo Without oil) & $71,7^{\mathrm{Aa}}$ & & $67,9^{\mathrm{Ab}}$ \\
Com óleo (With oil) & $69,4^{\mathrm{Ba}}$ & $\mathrm{Nmic}, \mathrm{g} / \mathrm{dia}$ & $67,7^{\mathrm{Ab}}$ \\
& $231,9^{\mathrm{Aa}}$ & & $227,1^{\mathrm{Aa}}$ \\
Sem óleo Without oil) & $203,1^{\mathrm{Ba}}$ & & $178,6^{\mathrm{Bb}}$ \\
Com óleo (Withoil) & &
\end{tabular}

$A, B$ Letras diferentes na mesma linha diferem Tukey $(P<0,05)$ (Different letters in same row differ, Tukey, $P<.05$ ).

$a, b$ Letras diferentes na mesma linha diferem, Tukey $(P<0,05)$ (Different letters in same row differ, Tukey, $P<.05$ ). 


\section{Discussão}

O consumo de matéria seca nas diferentes formas de expressão decresceu na presença de óleo de soja (Tabela 2), corroborando as afirmações de Allen (2000). A literatura tem abordado as limitações do consumo sob o ponto de vista de diferentes teorias, como resultado de complexas relações entre a dieta, o animal e as condições de alimentação e clima (Mertens, 1994).

As teorias existentes baseiam-se no enchimento do retículo-rúmen (Mertens, 1994), nos fatores de regulação metabólica (Illius \& Jessop, 1996) e no consumo de oxigênio (Ketelaars \& Tolkamp, 1996), entre outras. Isoladamente, uma única teoria não explica todas as variações possíveis sobre o consumo e, portanto, o NRC (2001) sugere que em muitas situações há um estímulo aditivo que regula o consumo voluntário.

Oconsumo de CFDNP (média de 1,11 kg FDN/100kg $\mathrm{PV}$, Tabela 2) nas dietas que não continham óleo aproximou-se do consumo máximo de FDN de 1,2\% do PV, como sugerido por Mertens (1994) para que vacas lactantes apresentem consumo ótimo de MS.

A presença de óleo elevou a concentração de NDT das dietas (75,3 vs 66,7\%), fazendo com que, apesar da redução no consumo, a quantidade de NDT ingerida fosse semelhante entre os tratamentos. Infere-se que o consumo das dietas contendo óleo pode ter sido limitado pelo incremento energético do óleo, associado ao baixo CFDNP (0,911 kg FDN/100 kg PV), o que, segundo Mertens (1994), caracterizaria a regulação fisiológica. No entanto, a adição de óleo ocasionou redução na produção de leite (22,4 vs 19,8 kg/dia), indicando menor aporte de nutrientes na glândula mamária ou o direcionamento destes para outras funções metabólicas. Neste sentido, Illius \& Jessop (1996) indicam que o desbalanço de nutrientes pode limitar o consumo, caracterizando-se como a assincronia de nutrientes à microbiota ruminal ou aos tecidos, em relação aos nutrientes absorvidos e metabolizados.

Os principais efeitos da adição de óleo sobre a redução do consumo estão relacionados à alteração da fermentação ruminal (Palmquist, 1994). A redução da digestibilidade da fibra no rúmen implica em um maior enchimento ruminal, aumentando o tempo de retenção da FDN no rúmen. Com exceção do EE, os tratamentos não influenciaram a digestibilidade total dos nutrientes (Tabela 3). Entretanto, as diferentes combinações de monensina e óleo de soja apresentaram comportamento diferente sobre a digestibilidade ruminal da FDN.
Nas dietas sem óleo, a monensina estimulou a digestão da fibra; porém, poucos trabalhos na literatura têm reportado este efeito (Shelling, 1984), que pode ser explicado pela redução das contrações ruminais na presença de monensina, aumentando o tempo de retenção da digesta no rúmen (Russel \& Strobel, 1989) e a ação do ionóforo sobre o controle de lactato no rúmen (Nagaraja et al., 1997). A dieta com óleo e sem monensina não interferiu na fermentação da fibra em relação à dieta com monensina somente, semelhantemente aos resultados de Bateman \& Jenkins (1998), que avaliaram a inclusão de até $8 \%$ de óleo de soja em dietas contendo $50 \%$ de volumoso.

A redução na digestibilidade ruminal da FDN observada na combinação de óleo e monensina sugere efeito direto sobre a população celulolítica ou sua atividade (Cant et al., 1997). Enquanto muitas das bactérias celulolíticas são sensíveis à monensina (Shelling, 1984), a digestibilidade ruminal da FDN na presença do ionóforo não é inibida, sugerindo que uma população celulolítica diferenciada, isto é, selecionada pela capacidade de resistência ou tolerância à monensina, consegue manter a atividade celulolítica no rúmen (Russel \& Strobel, 1989). Cant et al. (1997) e Clary et al. (1993) observaram que a presença de gordura na dieta aumentou a tolerância da população microbiana ao ionóforo. Este mecanismo foi também sugerido por Lana \& Russel (1996), ao observarem a depleção do potássio intracelular em experimentos in vitro.

Não foi verificado efeito de óleo ou monensina sobre o pH ruminal (Figura 1), corroborando as observações de Nagaraja et al. (1997). No entanto, o tempo em que o $\mathrm{pH}$ apresentou-se baixo pode ter influenciado a digestibilidade da fibra. A partir das equações de regressão de cada tratamento, calculou-se o tempo em que o $\mathrm{pH}$ permaneceu abaixo de 6,2: 4,8; 5,1; 1,7 e 5,7 horas, respectivamente, para as dietas óleo e monensina ausentes, presença de monensina, presença de óleo e combinação óleo e monensina. De acordo com de Veth \& Kolver (2001), a digestibilidade da FDN é reduzida quando o $\mathrm{pH}$ ruminal permanece quatro horas em valores abaixo de 6,0 e a síntese microbiana é reduzida quando o $\mathrm{pH}$ permanece 12 horas abaixo deste valor, indicando que a média do $\mathrm{pH}$, como também suas flutuações diárias, influenciam a atividade microbiana.

O maior tempo verificado com $\mathrm{pH}$ menor que 6,2 na combinação de óleo e monensina pode indicar maior efeito sobre a população de protozoários e sua ação no rúmen, uma vez que estes regulam o pH

R. Bras. Zootec., v.34, n.1, p.297-308, 2005 
ruminal, à medida que engolfam grânulos de amido, reduzindo a quantidade de substrato para a fermentação (Nagaraja et al., 1997). A literatura reporta efeito defaunatório quando gorduras insaturadas são adicionadas às dietas, principalmente aquelas ricas em ácidos linoléico e linolênico (Doreau \& Chilliard, 1997).

Doreau \& Ferlay (1995) reportam que uma característica principal da defaunação é a queda na concentração de $\mathrm{N}_{-} \mathrm{NH}_{3}$ no rúmen, decorrente da redução da atividade proteolítica dos protozoários. A interação observada entre óleo e monensina $(\mathrm{P}=0,0048)$ para $\mathrm{N}-\mathrm{NH}_{3}$ indica o efeito defaunatório do óleo, mas a maior concentração de $\mathrm{N}-\mathrm{NH}_{3}$ quando associado à monensina $(9,41$ vs $10,79 \mathrm{~g} / \mathrm{dL})$ pode indicar o menor aproveitamento do nitrogênio amoniacal pelas bactérias celulolíticas (Tabela 6 e Figura 2) e a redução da síntese microbiana em relação à dieta com óleo somente.

A eficiência de síntese microbiana (EfSM, Tabela 6) não foi afetada pelos tratamentos, entretanto, a síntese microbiana (Nmic) apresentou interação entre óleo e monensina $(\mathrm{P}=0,104)$. A presença de óleo reduziu a síntese microbiana e, quando associado à monensina, esta redução foi ainda maior, indicando efeito sinérgico negativo entre a gordura e o ionóforo. A diferença na síntese microbiana na presença de óleo pode ser explicada pela substituição de carboidratos fermentáveis do concentrado para a inclusão do óleo (Nagaraja et al., 1997). Além disso, deve ser considerado o efeito direto do óleo sobre a permeabilidade da membrana microbiana, que prejudica o funcionamento da célula e, portanto, reduz a síntese protéica (Doreau \& Ferlay, 1995). Possivelmente, o efeito defaunatório do óleo permitiu valores de EfSM similares entre os tratamentos; havendo diminuição no número de protozoários, provavelmente houve aumento do número de células bacterianas, resultante da redução da predação de bactérias pelos protozoários (Jenkins, 1993).

A concentração de AGV no líquido ruminal não foi afetada pelos tratamentos, ao passo que a proporção molar dos produtos finais da fermentação foi alterada, indicando alteração na população microbiana (Tabela 5). A proporção molar de acetato foi reduzida na presença de monensina ou de óleo, com maior magnitude de queda para a monensina (Tabela 6). A associação de óleo e monensina diminuiu a concentração de acetato em relação ao óleo, mas não deferiu da monensina, sugerindo que a população microbiana sensível à monensina não é a mesma que aquela sensível ao óleo de soja, ou também, que a microbiota ruminal apresenta diferentes graus de sensibilidade em relação ao ionóforo ou ao óleo de soja. Resultados semelhantes foram observados por Zinn (1988), utilizando graxa amarela e monensina.

Isoladamente, óleo e monensina elevaram a proporção molar de propionato e diminuíram a relação acetato:propionato (Tabela 5). A proporção molar de butirato foi reduzida na presença de óleo, o que indica redução no número ou na atividade de protozoários, sugerindo novamente efeito defaunatório (Nagaraja et al., 1997). Os valores observados para butirato estão próximos aos de Ikwuegbu \& Sutton (1982), que verificaram efeito linear negativo para a inclusão de até $40 \mathrm{~mL} /$ dia de óleo de linhaça na dieta de ovinos.

Enquanto a proporção molar de propionato elevou-se à custa de acetato, quando na presença de monensina, o propionato aumentou tanto pela diminuição de acetato como de butirato na presença de óleo de soja. Clary et al. (1993), citando Richardson et al. (1976), relatam que a energia bruta disponível ao animal avançou em 5,6\% quando a relação entre acetato, propionato e butirato alterou de 60:30:10 para 52:40:8, embora estas alterações nos produtos finais da fermentação nem sempre representem maior desempenho animal. Neste sentido, a associação de óleo e monensina, embora tenha alterado a proporção entre os AGV, reduziu a produção de leite, sugerindo com isto, que houve efeito sinérgico negativo, como relatado por Illius \& Jessop (1996) acerca do desbalanço de nutrientes.

Segundo Allen (2000), o consumo de matéria seca é determinado pelo conjunto de informações e sinais enviados ao centro da saciedade do cérebro. Este autor sugere que o propionato apresenta efeito supressor sobre o consumo, uma vez que estimula a síntese e liberação de insulina no sangue, ressaltando que os hepatócitos de ruminantes apresentam alta atividade de propionil-CoA sintetase e baixa de acetilCoA sintetase, o que poderia explicar a falta de resposta no consumo quando acetato foi infundido no sistema porta. No entanto, a modificação dos produtos finais da fermentação ruminal nas dietas com óleo, com aumento da proporção molar de propionato, não é suficiente para justificar a redução do consumo, pois a ingestão de matéria seca não foi reduzida na dieta com monensina somente. Associado a isto, Bateman \& Jenkins (1998) e Clary et al. (1993) não verificaram alteração na taxa de passagem de flui-

\section{R. Bras. Zootec., v.34, n.1, p.297-308, 2005}


dos, taxa de turnover de fluidos ou na taxa de diluição, quando gordura foi adicionada à dieta.

Palmquist (1994) sugeriu que a queda no consumo pode ser resultante do desbalanço de nutrientes utilizados no metabolismo ao invés do efeito sobre a digestibilidade da fibra ou ao atendimento das necessidades energéticas. Neste sentido, Shauff et al. (1992) observaram redução linear no consumo quando até $9,0 \%$ de gordura foi suplementada na forma de sabões de cálcio, não interferindo sobre os padrões de fermentação ruminal ou sobre a digestibilidade da FDN. Segundo Palmquist (1994), nos níveis intermediários de suplementação (3-6\%), a redução no consumo seria explicada pelo atendimento das exigências energéticas, enquanto, nos níveis mais altos de suplementação com sabões de cálcio (9\%), seria conseqüência do desbalanço. Estes sabões podem também ter se dissociado no rúmen, formando intermediários da bio-hidrogenação ruminal.

A redução do consumo de dietas ricas em gordura tem sido atribuída a fatores metabólicos envolvidos, como o estímulo à secreção de colecistoquinina (CCK), a oxidação de ácidos graxos no fígado e a síntese intestinal da apolipoproteína A-IV, relacionada como sinalizador de saciedade em ratos. Embora alguns resultados tenham sido obtidos com monogástricos, é possível que estes efeitos ocorram em ruminantes (Palmquist, 1994).

Para Allen (2000), a proteção dos ácidos graxos à bio-hidrogenação ruminal pode afetar o consumo por meio do maior acesso ao duodeno de ácidos graxos insaturados, que seriam absorvidos e metabolizados mais rapidamente no fígado, estimulando a liberação de CCK e de equivalentes redutores, que os ácidos graxos saturados resultantes da bio-hidrogenação ruminal.

Os resultados obtidos no presente trabalho estão de acordo com as observações de Allen (2000) acerca da influência dos ácidos graxos intermediários da bio-hidrogenação sobre o consumo. Utilizando tratamentos semelhantes e considerando que o perfil da gordura do leite seja similar ao dos ácidos graxos absorvidos no duodeno, Eifert (2004) verificou aumentos nas proporções dos ácidos graxos insaturados e dos isômeros trans- $\mathrm{C}_{18: 1}$ do leite quando na presença de monensina e de óleo, de forma similar ao deste trabalho. Foram observados aumentos nas concentrações de trans-10 $\mathrm{C}_{18: 1}$ e redução no teor de gordura proporcional às concentrações deste ácido graxo. Isômeros trans c18:1 e CLA trans-10 cis-12
C18:2 estão envolvidos na queda do teor de gordura, na inibição de enzimas chave na síntese de novo e, em altas concentrações, nas reduções da produção de leite e do consumo (Bell \& Kennelly, 2003). Allen (2000) tem sugerido que os ácidos graxos insaturados de cadeia longa e os isômeros gerados na biohidrogenação ruminal podem influenciar negativamente o consumo, propondo a realização de experimentos com infusão abomasal para determinar os efeitos de específicos isômeros C18:1 e C18:2 sobre o consumo de matéria seca.

\section{Conclusões}

A fermentação ruminal é alterada quando da adição de monensina ou óleo de soja às dietas. A combinação destes dois aditivos aparentemente altera a população microbiana ou seu crescimento de forma diferente que quando se utiliza óleo ou monensina em separado, refletindo em efeitos inibitórios sobre a digestão da fibra.

A limitação no consumo pelo efeito de enchimento ruminal, a partir da redução da digestibilidade da FDN ou pelo incremento energético, não justifica a redução no consumo de matéria seca nas dietas com óleo, indicando que fatores metabólicos podem estar envolvidos.

\section{Literatura Citada}

ALLEN, M.S. Effects of diet on short-term regulation of feed intake by lactating dairy cattle. Journal of Dairy Science, v.83, p.1598-1624, 2000.

BATEMAN, H.G.; JENKINS, T.C. Influence of soybean oil in high fiber diets fed to nonlactating cows on ruminal unsaturated fatty acids and nutrient digestibility. Journal of Dairy Science, v.81, p.2451-2458, 1998.

BELL, J.A.; KENNELLY, J.J. Short communication: postruminal infusion of conjugated linoleic acids negatively impacts milk synthesis in Holstein cows. Journal of Dairy Science, v.86, p.1321-1324, 2003.

CANT, J.P.; FREDEEN, A.H.; MacINTYRE, T. et al. Effect of fish oil on milk composition in dairy cows. Canadian Journal of Animal Science, v.77, p.125-131, 1997.

CHANEY, A.L.; MARBACH, E.P. Modified reagents for determination of urea and ammonia. Clinical Chemistry, v.8, p.130-132, 1962.

CHEN, X.B.; GOMES, M.J. Estimation of microbial protein supply to sheep and cattle based on urinary excretion of purine derivatives - an overview of technical details. Bucksburnd, Aberdeen: Rowett Research Institute, 1992. 21p. (Occasional publication)

CLARY, E.M.; BRANDT JR., R.T.; HARMONT, D.L. et al. Supplemental fat and ionophores in finishing diets: feedlot performance and ruminal digesta kinetics in steers. Journal of Animal Science, v.71, p.3115-3123, 1993.

R. Bras. Zootec., v.34, n.1, p.297-308, 2005 
COCHRAN, R.C.; ADAMS, D.C.; WALLACE, J.D. et al. Predicting digestibility of different diets with internal markers: Evaluation of four potential markers. Journal of Animal Science, v.63, p.1476-1483, 1986.

de VETH, M.J.; KOLVER, E.S. Diurnal variation in $\mathrm{pH}$ Reduces Digestion and Synthesis of Microbial Protein when Pasture is Fermented in Continuous Culture. Journal of Dairy Science, v.84, p.2066-2207, 2001.

DOREAU, M.; CHILLIARD, Y. Digestion and metabolism of dietary fat in farm animals. British Journal of Nutrition, v.78, Suppl. 1, p.S15-S35, 1997.

DOREAU, M.; FERLAY, A. Effect of dietary lipids on the ruminal metabolism in the rumen: a review. Livestock Production Science, v.43, p.97-110, 1995.

EIFERT, E.C. Fontes de carboidratos, óleo de soja e monensina para vacas lactantes: desempenho, digestibilidade, parâmetros ruminais e perfil de ácidos graxos do leite. Viçosa, MG: Universidade Federal de Viçosa, 2004. 117p. Tese (Doutorado em Zootecnia) Universidade Federal de Viçosa, 2004.

ILLIUS, A.W.; JESSOP, N.S. Metabolic constrains on voluntary intake in ruminants. Journal of Animal Science, v.74, p.3052-3062, 1996.

IKWUEGBU, O.A.; SUTTON, J.D. The effect of varying the amount of linseed oil supplementation on rumen metabolism in sheep. British Journal of Nutrition, v.48, p.365-375, 1982.

JENKINS, T.C. Symposium: Advances in ruminant lipid metabolism - Lipid metabolism in the rumen. Journal of Dairy Science, v.76, p.3851-3863, 1993.

KETELAARS, J.J.H.M.; TOLKAMP, B.J. Oxygen efficiency and the control of energy flow in animals and humans. Journal of Animal Science, v.74, 3036- 3051, 1996.

LANA, R.P.; RUSSELL, J.B. Use of potassium depletion on growth to assess adaptation of ruminal bacteria to ionophores. Applied Environmental Microbiology, v.56, p.1588-1593, 1996.

LEÃO, M.I.; VALADARES FILHO, S.C.; RENNÓ, L.N. et al. Consumos e digestibilidades totais e parciais de matéria seca, matéria orgânica, proteína bruta e extrato etéreo em novilhos submetidos a três níveis de ingestão e duas metodologias de coleta de digestas abomasal e omasal. Revista Brasileira de Zootecnia, v.33, p.1604-1615, 2004.

MERTENS, D.R. Regulation of forage intake. In: FAHEY JR., G.C. (Ed.) Forage quality, evaluation and utilization. Madison: American Society of Agronomy, 1994. p.450-493.

NAGARAJA, T.G.; NEWBOLD, C.J.; Van NEVEL, C.J. et al. Manipulation of ruminal fermentation. In: HOBSON, P.N.; STEWART, C.S. (Eds.). The rumen microbial ecosystem. 2.ed. Great Britain: Blackie Academic \& Professional, 1997. p.524-632.

NATIONAL RESEARCH COUNCIL - NRC. Nutrient requirements of dairy cattle. 7.ed. Washington, D.C.: National Academy, 2001. 381p.

PALMQUIST, D.L. The role of dietary fats in efficiency of ruminants. Conference: regulating lipids metabolism to increase productive efficiency. Journal of Nutrition, v.124, p.1377S-1382S, 1994.
RENNÓ, L.N. Consumo, digestibilidade total e parcial, produção microbiana, parâmetros ruminais e excreções de uréia e creatinina em novilhos alimentados com dietas contendo quatro níveis de uréia ou dois níveis de proteína. Viçosa, MG: Universidade Federal de Viçosa, 2003. 252 p. Tese (Doutorado em Zootecnia) - Universidade Federal de Viçosa, 2003.

RUSSELL, J.B.; STROBEL, H.J. Effect of ionophores on ruminal fermentation. Applied Environmental Microbiology, v.55, p.1-6, 1989.

STATISTICAL ANALYSES SYSTEM - SAS. User's guide. Version 6.12 4.ed. v.1. Cary: 1997. 890p.

SHAUFF, D.J.; CLARK, J.H. Effects of feeding diets containing calcium salts of long-chain fatty acids to lactating dairy cows. Journal of Dairy Science, v.75, p.2990-3002, 1992.

SCHELLING, G.T. Monensin: mode of action in the rumen. Journal of Animal Science, v.58, p.1518-1527, 1984.

SILVA, D.J, QUEIROZ, A.C. Análise de alimentos (Métodos químicos e biológicos). Viçosa, MG: Universidade Federal de Viçosa, 2002. 235p.

SNIFFEN, C.J.; O'CONNOR, J.D.; Van SOEST, P.J. et al. A net carbohydrate and protein system for evaluating cattle diets: II- Carbohydrate and protein availability. Journal of Animal Science, v.70, p.3562-3577, 1992.

SUKHIJA, P.S.; PALMQUIST, D.L. Rapid method for determination of total fatty acid content and composition of feedstuffs and feces. Journal of Agricultural Food Chemistry, v.36, p.1202-1206, 1988.

VALADARES, R.F.D.; BRODERICK, G.A.; VALADARES FILHO, S.C. et al. Effect of replacing alfafa silage with high moisture corn on ruminal protein synthesis estimated from excretion of total purine derivates. Journal of Dairy Science, v.82,p.2686-2696, 1999.

Van SOEST, P.J.; ROBERTSON, J.B.; LEWIS, B.A. Methods for dietary fiber, and nonstarch polysaccharides in relation to animal nutrition. Journal of Dairy Science, v.74, p.3583-3597, 1991.

Van SOEST, P.J. Nutritional ecology of the ruminant. Ithaca: Comstock Publ. Association, 1994. 476p.

VERBIC, J.; CHEN, X.B.; MACLEOD, N.A. et al. Excretion of purine derivatives by ruminants: Effect of microbial nucleic acid infusion on purine derivative excretion by steers. Journal of Agricultural Science, v.114, p.243-248, 1990.

ZINN, R.A. Comparative feeding value of supplemental fat in finishing diets for feedlot steers supplemented with or without monensin. Journal of Animal Science, v.66, p.213-227, 1988. 